\title{
Study on Basic Vowels in Mongolian Based on PAS
}

\author{
SU Min ${ }^{1^{*}}$, YU Hongzhi ${ }^{1}$ \\ Key Lab of China's National Linguistic Information Technology, Mongolian Language and Culture \\ Institute, Northwest University for Nationalities \\ Lanzhou, China 730030 \\ email:bhbhsumin@163.com
}

Keywords: Mongolian. Basic Vowels. physiologic parameters.

Abstract. Using PAS 6600, the physiologic parameters of basic vowels in Mongolian were extracted in the process of pronunciation, which includes expiratory airflow duration(EAD), peak expiratory airflow(PEA), expiratory volume(EV) and aerodynamic resistance(AR). Through statistical analysis of the extracted parameters, it shows the nature of tense/lax vowels in Mongolian is the result of interaction between the vocal cords and tongue position. This paper also indicates different phonemes formed in the Internal of tense/lax vowels mainly due to the position change of tongue.

\section{Introduction}

Using laboratory equipment PAS 6600 in phonetics study has long history .In the early study, the device is mainly used for respiratory disease and lung function insufficient in patients to measure the air flow and pressure in breathing and phonation [1]. In the 1870s, Fant and Gauffin in KTH study phonetics combined with speech aerodynamics. To collect the signals of air flow and pressure through the device in different states of speech and explore changes in vocal cords, especially the vocal organ, tune and so on, which are not easily observed directly by the people. In China, the Mongolian basic vowels have gender distinctions. Generally, negative vowels are known as lax vowels and positive vowels are known as tense vowels. Chinese Mongolian belongs to Mongolian language branch in Altaic language family. There are eight basic vowels in Chinese Mongolian: [a] $[0],[\mho],[\mathrm{I}],[\mathrm{\partial}],[\mathrm{o}],[\mathrm{u}],[\mathrm{i}]$. This paper is on the use of PAS 6600 to study the airflow mechanism of eight basic vowels in Mongolian Standard on the basis of previous studies .the experimental study shows the reasons of the produce of lax and tense in Mongolian basic vowels and the different phonemes inside the lax and tense vowel.

\section{Experimental Methods}

Instrument Introduction. Phonatory aerodynamic system 6600 (PAS 6600), which was produced by KAY. Hardware modules are composed by mask airflow, pressure sensors, microphones, etc. After connecting to the computer, it can capture phonation time, peak expiratory and other physiological parameters of speech, which is an important tool of physiological analysis of speech. a comfortable and quiet pronunciation environment is needed to ensure the stability and authenticity of the speech signal. 
Speaker speech and pronunciation material. The experiment selects two speakers including a man and a woman, whose Mother tongue are Mongolian and Pure voice, no hearing impairment and the history of voice disorders. At the time of extraction, when men and women did not differ significantly, the experiment data is based on the male speakers' parameters. Pronunciation material is the eight basic vowels, which is from The Test Outline of Mongolian Standard. There are four lax vowels including $[\mathrm{a}] 、[\mathrm{o}],[\mathrm{\sigma}],[\mathrm{I}]$ and four tense vowels including[ə]、[o]、[u]、[i]. In the recording process, each basic vowel is read three times. Then there are 21 voice samples totally.

\section{Experiment Analysis}

Through the induction to the acquisition physical parameters, physical parameters Form get finally. The following are the analysis to those physical parameters to reflect the feature of basic vowel in Mongolian.

TABLE I. Physiological parameter of basic vowel in Mongolian

\begin{tabular}{|l|c|c|c|c|c|c|c|c|}
\hline & $\mathrm{a}$ & J & v & I & ə & o & u & i \\
\hline EAD(s) & 0.07 & 0.06 & 0.07 & 0.06 & 0.06 & 0.05 & 0.07 & 0.05 \\
\hline $\mathrm{PEA}(\mathrm{Lit} / \mathrm{Sec})$ & 0.23 & 0.21 & 0.12 & 0.49 & 2.03 & 1.57 & 3.44 & 1.31 \\
\hline $\mathrm{EV}(\mathrm{Lit} / \mathrm{Sec})$ & 0.008 & 0.007 & 0.005 & 0.017 & 0.109 & 0.061 & 0.217 & 0.052 \\
\hline $\mathrm{AR}(98.0665 \mathrm{~Pa} / \mathrm{Lit} / \mathrm{Sec})$ & 50.12 & 116.40 & 138.24 & 30.92 & 17.31 & 15.66 & 22.59 & 10.37 \\
\hline
\end{tabular}

Expiratory airflow duration. $[\mathrm{a}] 、[\mathrm{\partial}] 、[\mathrm{\rho}] 、[\mathrm{o}] 、[\mathrm{v}] 、[\mathrm{u}] 、[\mathrm{I}] 、[\mathrm{i}]$ are relative in Mongolian basic vowel. Comparison the lax vowel with the corresponding tense vowel can be more intuitive to see the difference in EAD. The EAD of vowel can reflect the time of vocal fold vibration when vowel pronunciation. The longer of the EAD, the longer of the time of vocal fold vibration. It is easy to find :1) the EAD of the tense vowel is longer than the corresponding lax vowel, which is determined by the vocal cord and the position of the tongue. 2) There is no difference in the EAD of lax/tense vowel. The EAD of the lax/tense vowel provide a reference to PEA、EV and AR.

Peak expiratory airflow. In physical, the PEA of basic vowel can reflect the opening degree of vocal cord in pronunciation. From the comparison of PEA and EAD, we can find: 1) The maximum speed of gas outflowing the glottal unit time in lax vowel is significantly higher than the tense vowel, which indicates the vocal cord of lax vowel is relative, while the tense vowel is tight in pronunciation. 2) from the relationship of the PEA and EAD: the PEA of lax vowel is proportional to the EAD and the PEA of tense vowel is inversely proportional to the EAD, which shows tense vowel is relatively stable in the unit time, namely, In the course of pronunciation of the vocal cords continued tension.

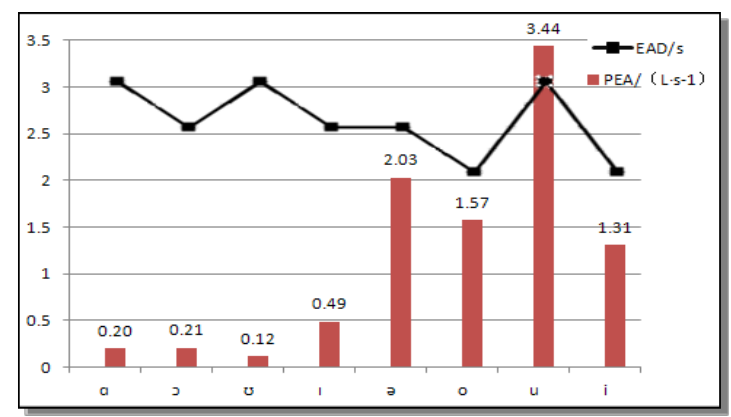

Fig 1. The comparison to PEA and EAD 
Expiratory volume. expiratory volume is equal to expiratory airflow duration and equal volume, which reflects the steady air flow provided by the lungs. It is easy to find from figure 2:1) The of lax is larger than the tense, proportional to EAD. 2) There is a significant relationship between EV and Place of articulation.

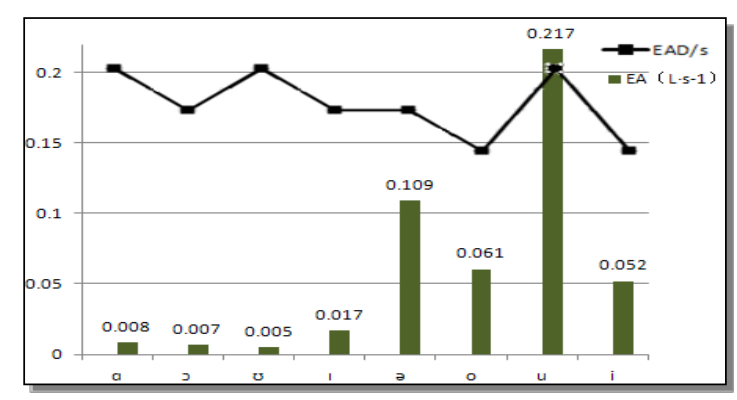

Fig 2. The comparison to EV and EAD

Aerodynamic resistance. aerodynamic resistance is Proportional to the tension of vocal. In the course of the pronunciation The investigation of aerodynamic resistance can reflect the mode of vocal cords vibration. from Figure 3: 1) The basic vowels in Mongolian the aerodynamic resistance of tense vowel is generally greater than the lax., which indicates that the vocal cords of the tense is tight, the lax is contrary. 2) In tense vowel, AR and PEA have an inverse proportion relation, however it is contrary in the lax vowel. 3) Generally, AR is related to PEA. From Figure 5: the longer of the EAD, the larger of the AR in lax vowel. AR is unrelated to EAD in tense vowel.

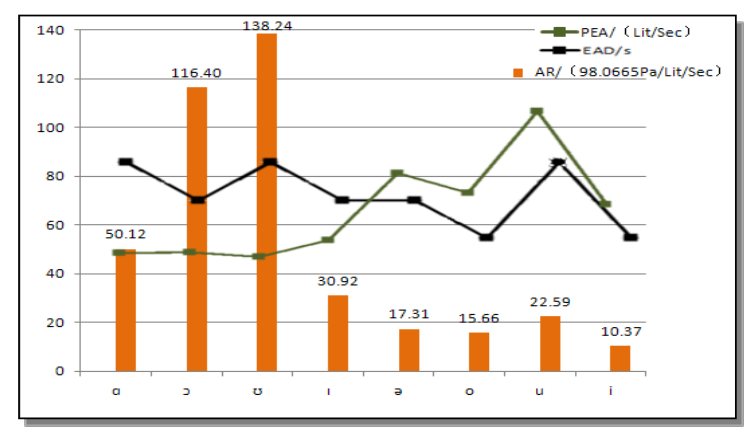

Fig 3. The comparison to AR,PEA and EAD

\section{Discussion}

The generation of speech is divided into two parts, One part is resonance, and the other is the sound source. In phonetics, the former corresponds to the opening size, which is called articulation. The later corresponds to the vibration of vocal cords, which is called phonation [2]. The article indicates the Physiological parameters of eight basic vowel in Mongolian to show Mongolian basic vowel is the result of the interaction of articulation and phonation.

Subglottic system. The gender of Mongolian basic vowel is decided by vocal. The size of expiratory volume through PAS6600 is mainly controlled by glottis and is closely related to the tension of vocal. Aerodynamic resistance of tight vowels is smaller and peak expiratory airflow is smaller in the process of the pronunciation, corresponding to the small area of glottis in physiological, which shows the vocal cords are tight in the pronunciation in tense vowel. In the tight vowels, the longer of the EAD, the smaller the PEA, which indicates that the air flow through the vocal cords in the unit time is stable, and the vocal cords remain tight in the; In the pronunciation of lax vowel, the vocal cords are in a state of relaxation, which mainly depends on the modulation of 
the oral cavity. Therefore tight vowels of Mongolian are influenced by the glottis, vocal cord keep equilibrium tension in the process. The influence of glottis to lax vowels in the pronunciation is small, which is mainly determined by position of the tongue, the size of the opening and the length of the time.

Supraglottic system. Tongue is the most important factor in the vowel. Mongolian basic vowels are related to the position of tongue. Tongue forward keep the flow of air current, Tongue back will inevitably lead to the uplift of the epiglottis, which will block the air flow channel. In terms of PEA or EV, tense vowels are lower than lax, which has the a big relations to the position of the tongue back, causing epiglottis backward and blocking flow channel.

From the inside of tense/lax vowel, the relationship between EV and EAD is not significant. Then EV and the position of the tongue in the vocal cord tension have great relationship. For example, the EV of $[\mathrm{I}]$ is more than $[\mathrm{a}] 、[0],[\mathrm{\mho}]$. Tense vowel in the back of tongue is related to opening degree. The larger of the opening degree, the more of the EV; the interior of the lax also has this kind of phenomenon.

\section{Conclusion}

The research of traditional Mongolian grammar that Mongolian basic vowels have sex, this difference is mainly reflected in the different parts of pronunciation. In this paper, extracting physiological parameters through PAS6600, It points out that the difference of tense/lax vowels in Mongolian basic vowel is the results of interaction of articulation and phonation: pronunciation time is longer in tense vowels and vocal cords maintain a balanced tension and the tongue is backward at the same time; the pronunciation time of lax vowels is short and the vocal cords are relaxed and the tongue is relatively forward. Meanwhile different phonemes of tense/lax vowels are formed mainly through oral cavity modulation.

There are some problems to be solved in the experiment. 1) Because of the differences in pronunciation and pronunciation methods, it needs to be further processed to data. 2) Vowels in pronunciation process will be accompanied by vocal cords vibration. Therefore, research on Mongolian basic vowels should also with the voice.

\section{References}

[1] Shadle C H. The Aerodynamics of Speech. In The Handbook of Phonetic Science[M]. Oxford: Blackwell. 1997.

[2] KONG Jiangping. On Language Phonation [M]. Minzu University of China Press.2001. （in Chinese )

[3] HU he. Research on Mongolian phonetic experiment[M]. Liaoning Nationalities Publishing House. 2009:23f. （in Chinese）

[4] BAO Guilan. EPG-based research on co-articulation in standard Mongolian in China[D]. 2011. (in Chinese)

[5] HU.Axu, LV Shiliang, Gegentana, YU Hongzhi. Speech aerodynamics of standard Mongolian lax/tense vowels [M]. Journal of Tsinghua University(Science and Technology), 2011:9. (in Chinese ) 